\title{
Участие органов ОГПУ \\ в осуществлении раскулачивания в Омском регионе Западной Сибири
}

\begin{abstract}
Аннотаиия. Статья посвящена актуальной проблеме участия и меры ответственности местных органов ОГПУ в прочессе раскулачивания и выселения кулаков в необжитые районы. В исторической литературе по этому вопросу сложилось две точки зрения. Одни ученые возлагают ответственность за раскулачивание челиком на ОГПУ, другие распределяют ответственность между различными партийными и государственными органами формирующейся командно-административной системъ. Основу исследования составляли архивнье документы Государственного архива Новосибирской области, поскольку Новосибирск был в рассматриваемое время столичей края. Автор обрашается к методологии системного анализа и дополняет его прочессуальным подходом, заимствованным из соииологии. Это позволяет сделать акиент на динамике развития ситуаиии, действиях различных акторов и совокупным результатом их действий. Обосновывается вывод, что иниииатива, идеологчческое обоснование и проведение раскулачивания принадлежали партийно-государственному аппарату. На местные органы ОГПУ возлагалось планирование операчий, координачия действий различных органов административного аппарата и информирование высших органов власти об изменении оперативной установки. Раскулачивание проводилось при поддержке колхозного актива на местах. Таким образом, работала целая система уничтожения зажиточного крестьянства.
\end{abstract}

Ключевые слова: ОГПУ, кулаки, раскулачивание, выселение, план, перегибы, уполномоченные, партактив, Административное управление, побеги.

Abstract. The article is dedicated to the current historiographical issue concerning the participation of the Joint State Political Directorate (JSPD) agencies in the dekulakisation and dispossession process of wealthier peasants (Kulaks) in outback regions. Scientific literature reflects two different points of view on this question. Some scientists place the entire dekulakisation responsibility on the Joint State Political Directorate, while others allocate this responsibility among various party and government bodies of the still forming state command and administrative system. The basis of this research is archival material from the State Archive of the Novosibirsk region, as Novosibirsk at the time was considered to be the region's capital. The author applies the methodology of the system analysis to this study and complements it with the procedural approach taken from sociology. This has allowed to focus on the situation's dynamic development, on the behaviour of various participants and to reveal the cumulative result of their activities. The author corroborates his conclusion that the initiative, ideological substantiation, and the dekulakisation process belonged to the party and government systems. Local JSPD agencies were assigned with planning the operations, coordinating the activities of the different administrative agencies, and informing the higher authorities about the changes in the operative situation. Thus, there was a whole system in place for the eradication of the wealthy peasantry.

Key words: Joint State Political Directorate (JSPD), Kulaks, Dekulakisation, dispossession, plan, excesses, commissioners, party activists, Administrative Department, escapes.

Пема коллективизации и раскулачивания в СССР, а также участие в этих процессах органов ОГПУ до сих пор вызывает споры в стране и в научном сообществе историков. Дискуссия продолжается не только на уровне «большого» общества, но и на уровне региональной истории, например, региона Западной Сибири. Немецкому населению Западной Сибири, представленному по преимуществу крестьянами, которое испытало коллективизацию и раскулачивание, репрессивную политику ОГПУ-НКВД в 1920-1930-е гг.

Статья подготовлена при поддержке правительства Омской области (грант правительства Омской области № 0152200001315000067, лот № 1 om 16.07.2015 г.) 


\section{Исторический журнал: научные исследования № 2 (32) • 2016}

DOI: 10.7256/2222-1972.2016.2.17518

посвящены монографии Л.П. Белковец и В.И. Бруля $[1,2$.$] . Репрессии в отношении тюркских$ народов Западной Сибири при проведении коллективизации исследует О.А. Озерова $[8,9$, 10.]. Высылке крестьян в Западную Сибирь посвятил С.А. Красильников свою монографию и статью, написанную совместно с С.Н. Ушаковой $[5,6$.$] . Не стала исключением Омская область,$ где проблема ответственности местных чекистов за раскулачивание обсуждается довольно оживленно. О репрессиях в отношении трудового крестьянства Омского Прииртышья пишет в своей книге М.С. Шангин, подкрепляя изложение многочисленными документами [12.]. Историк В.Ф. Зима подчеркивал в своих работах решающую роль органов ОГПУ в процессе раскулачивания на селе: «Решающую роль в этой, по словам Сталина, "хирургической операции" он отводил ОГПУ. Все руководство осуществлялось партийными органами» [4 C.82.]. То есть, по мнению ученого, аппарат спецслужб был основным инструментом в руках большевистского руководства по проведению репрессий в отношении кулачества. В.Ф. Зиме возражает C.A. Папков, который утверждает, что в борьбе с кулачеством ведущая роль принадлежала местному партийно-государственному аппарату. Он отмечает также поддержку борьбы с кулаком со стороны социальных низов деревни, каковую поддержку государство подкрепило передачей $25 \%$ конфискованного у кулаков хлеба. С.А. Папков, в частности, пишет: «Основная роль в организации ликвидации кулаков принадлежала районному “активу" во главе с райкомами ВКП(б) и райисполкомами, а исполнительные функции находились в руках различных уполномоченных из числа членов сельских советов, коммун, партячеек, комсомольцев, учителей местных школ, представителей бедноты - в оперативном порядке сформированных тем же районным активом. ... Процедура экспроприации зависела исключительно от самих “экспроприаторов" [11 C. 33-34, 51-52.]. То есть к концу 20-х годов в деревне созрели предпосылки для борьбы с зажиточным крестьянством.

Омский исследователь В.П. Василевский в своей диссертационной работе делает обтекаемый вывод: «На органах ОГПУ, выполнявших приказы партийно-государственного руководства, лежит частичная ответственность за репрессии в деревне. При этом следует учитывать, что сопротивление коллективизации делало неизбежным участие органов государственной без- опасности в ее проведении». То есть, принудительная коллективизация под страхом раскулачивания не могла не вызвать противодействие возмущенного крестьянства, а это сопротивление автоматически запускало машину советской политической полиции. При этом В.П. Василевский возлагает основную ответственность за репрессии в деревне на местный партийно-государственный аппарат и активистов из числа деревенской бедноты, «которые активно поддерживали их проведение и имели материальную заинтересованность в раскулачивании более состоятельных односельчан» [3 С.209.].

Следует сразу отметить, что предмет спора сильно политизирован, поэтому требует осторожности в выводах и обобщениях. По этой же причине выводы необходимо строить на основе дошедших до нас документов эпохи. Однако при рассмотрении проблемы участия органов ОГПУ в раскулачивании В.П. Василевский в своей диссертации опирается в основном на опубликованные источники. Между тем, в фондах бывшего партийного архива Новосибирской области хранится немало документов по указанной проблеме, поскольку в период проведения коллективизации Новосибирск был региональной столицей Западносибирского края, и большинство документов о выселении и приеме кулаков на спецпоселения осели в новосибирских архивных фондах.

Согласно обнаруженным документам, в Омском округе за один год коллективизации (1930/1931) было раскулачено 8430 крестьянских хозяйств из общего числа 148661 , то есть 4,6\% дворов [13 Л.15об.]. При этом инициатива и руководство выселением кулаков действительно принадлежала местной партийной организации. Для ее проведения были назначены специальные уполномоченные от партийных комитетов. Как именно было организовано выселение в Омском округе, можно судить по отчету о выселении кулацких семей 13 января 1931 г., которое осуществлял уполномоченный окружкома Спиров. Было запланировано к выселению 50 семей, но фактически было выселено 22 семьи (всего 82 человека, из них 50 взрослых и 32 ребенка). Им предоставили 22 лошадей, 22 саней, рабочий инструмент, продовольствия и фуража на два месяца, и в 15 часов по местному времени погрузили в железнодорожные вагоны для отправки в спецкомендатуру в Чанский район [13 Л.1, 2.]. При этом сам Спиров просил руководство отложить отправку спецпереселенцев, 
Социальная история

DOI: $10.7256 / 2222-1972.2016 .2 .17518$

поскольку они не были полностью обеспечены натурпродуктами (не предоставили выселяемым овса для лошадей), но получил жесткую жесткий приказ осуществить погрузку вовремя.

Документы свидетельствуют также, что под кампанию выселения попадали не только одни зажиточные крестьяне. Так, в сводке по высылке кулаков в Омском оперативном секторе за апрель 1933 года кроме местных кулаков (разделенных на «полносемейных» и «одиноких») и «беглого кулачества» под выселение попали: саботажники, «снимаемые с должности в промышленных предприятиях» и нищинствуюшие элементы [13 Л.443.]. То есть, местные власти подводили под развернувшуюся в стране кампанию не только зажиточную часть крестьян в сельской местности, но и «неудобные» с точки зрения властей элементы в городе. Хотя у автора предлагаемой статьи есть подозрение, что при «чистке» предприятий, прежде всего, учитывалось социальное происхождение (то есть, «чистили» выходцев из деревни, из зажиточных семей). В пользу этого говорит тот факт, что «кулаков» высылали не только из сельской местности, но и из городов тоже. Но большую часть выселенных составляли «выселяемые из районов сплошной коллективизации» - 3361 человек из общего числа 3964 выселенных [14 Л.443.].

Документы подтверждают, что органы ОГПУ принимали прямое участие в планировании и организации этих переселений. В частности, об этом говорит «Докладная записка по вопросу 40 тысяч выселяемых хозяйств сибирского кулачества в северные районы края», подписанная полномочным представителем ОГПУ по Западносибирскому краю Л.М. Заковским и начальником секретно-политического отдела ПП ОГПУ Лупекиным. Дата на документе отсутствует, но его можно условно датировать второй половиной 1931 г. В документе подробно изложен план операции по выселению в 1932 г. около 160000 человек в северные малообжитые районы Западносибирского края - Каргасокский, Чаинский, Колпашевский, Зырянский, Сусловский и Новокусковский на шестьдесят выделенных заранее незаселенных участков, которые переселенцам предстояло расчистить и раскорчевать самим [13 Л.205-218.].

В документе подробно прописана процедура выселения, указано, какими силами оно будет проводиться: «на местах производится внутренняя мобилизация всего райаппарата ОГПУ и милиции, с максимальным использованием партий- ного, комсомольского и колхозного актива» [13 Л.215.]. Для сопровождения выселяемых с места жительства до баз погрузки выделялся конвой из милиции и колхозного актива. На станциях при погрузке в эшелоны выселяемые поступали в распоряжение коменданта поезда, назначенного транспортным отделом ОГПУ. На местах для приема спецпереселенцев создавались участковые комендатуры. Продукты, инвентарь, скот, фураж переселенцам выделяли хозяйственные органы, медицинская служба обеспечивала медицинское обслуживание во время пути и в местах расселения. Таким образом, в операции по выселению кулачества принимал участие весь государственный аппарат. Органам ОГПУ принадлежала роль координаторов и наблюдателей: на них возлагалось так называемое «чекистское обслуживание» спецпереселенцев через специальных уполномоченных в пути и создание сети осведомителей на местах [13 Л.217.].

Таким образом, если инициатива, идеологическое обоснование выселения кулачества, а также его организация принадлежала партийно-государственному руководству страны, то непосредственное планирование, координация и надзор за проведением операций осуществляло ОГПУ. Ответственность за осуществление репрессий в отношении зажиточных крестьян, таким образом, в равной степени лежит на партийно-государственном аппарате, органах ОГПУ и местном «колхозном активе» из бедняков.

Одной из функций ОГПУ было постоянное информирование руководства об объективном положении дел в стране. В качестве примера В.П. Василевский приводит записку о политических настроениях в Сибири в связи с коллективизацией и раскулачиванием, поданную Сталину Г.Г. Ягодой и Е.Г. Евдокимовым. В записке приводились многочисленные факты массового произвола и о преступлениях, совершаемых местными партийными и советскими работниками при проведении раскулачивания [3 С.206207.]. В документе Омский округ были отнесен к округам «наиболее пораженным в отношении искривлений и перегибов» [7 С. 236.] .

Однако подобные докладные записки о злоупотреблениях регулярно поступали партийному руководству страны и Западносибирского края и в последующее время. Так, 10 июня 1933 г. секретарю Западносибирского крайкома ВКП(б) было прислано внеочередное донесение Полномочного представительства ОГПУ по Западносибирскому краю. В донесении при- 


\section{Исторический журнал: научные исследования № 2 (32) • 2016}

DOI: $10.7256 / 2222-1972.2016 .2 .17518$

водились факты многочисленных «перегибов» при проведении чисток колхозов в одном из районов Омского округа [15 Л.32-33.].

Некоторые из приведенных в донесении фактов можно назвать вопиющими: «Лишен избирательных прав и вычищен из колхоза Ровкин И.В. середняк-колхозник, бригадир-ударник, колхозники говорят что «благодаря Ровкина и его бригады обеспечено было стадо сеном». В 1931 г. был колхозом командирован на работу в Кузнецкстрой, от последнего имеет грамоту ударника, в колхоз вступил в 1929 г., два сына в Красной Армии. После исключения Ровкина разбило параличом» [15 Л.32-33.]; «батрачкой Кузьменкиной даны справки, что она батрачила у целого ряда кулаков, при проверке справок оказалось, что Кузьменкина выдала справок, что она батрачила с 1925 по 1929 г. у разных лиц до 150 месяцев, т.е. по 30 месяцев в год». «Кабанским с/советом дана справка, что Шадрин Андрей жил в батраках у кулака Портнягина Дмитрия в течение 1 лет, тогда как при проверке оказалось, что хозяйство Шадрина по доходности крепче х-ва Портнягина и в батраках он у последнего не жил» [15 Л.32-33.].

Всего по району было раскулачено 64 хозяйства, при продаже имущества в ряде случаев распродавались все вещи, включая белье и предметы обихода. При этом скупщиками на этих торгах чаще всего выступали «низовые работники» сельских советов.

Представляется, что описанные случаи для рассматриваемой эпохи были типичными. Стоит согласиться с утверждением В.П. Василевского о тот, что «сигналы, исходившие от органов государственной безопасности руководству партии о взрывоопасной ситуации в деревне, в первую очередь, были в интересах правящей партии, поскольку массовые перегибы на местах грозили привести к крестьянскому восстанию по всей Сибири» [3 С.208.]. Недаром процитированное выше донесение было испещрено пометками Л.И. Картвешвили (второго секретаря Западносибирского краевого комитета ВКП(б)), адресованными работникам аппарата краевого комитета Кудрявцеву, Осипову, Лесновой с требованием принять по выявленным фактам меры. Однако далее Василевский берет на себя смелость утверждать, что «подобные сигналы органов государственной безопасности наверх в какой-то мере защищали крестьян от произвола представителей партийно-государственного аппарата на местах». На самом деле
ОГПУ в это время уже было спецслужбой, совершенно лишенной собственной идеологии, в отличие от ВЧК времен Ф.Э. Дзержинского, в которой собственная идеология все-таки присутствовала. Органы ОГПУ стремились четко и әффективно выполнить поставленную руководством задачу: освещать ситуацию в стране наиболее оперативно и полно. Защита несправедливо пострадавших от «искривлений и перегибов» было побочным следствием этого стремления.

$$
* * *
$$

Отличительной чертой Сибири от Европейской России было и то, что при советской власти, как и при царском режиме, она продолжала оставаться местом ссылки. Это рождало неприятную для местных властей коллизию: кроме собственных кулаков им нужно было размещать в комендатурах людей, перемещенных из-за Урала. Например, согласно докладу «О административно-хозяйственном управлении спецпереселенцев» за 1931 год за одну весну 1930 года в Сибирском крае было выселено на территорию спецкомендатур 16113 кулацких семей, всего 80804 человек. Кроме того, в Сибирь было перевезено 19958 человек украинских кулаков (из них, что очень важно для понимания дальнейших событий, 13000 бессемейных одиночек). Таким образом, спецкомендатурами было принято от ОГПУ 100762 человек [13 Л.21.].

И, хотя после разделения Сибирского края на Западную и Восточную Сибирь на территории Западносибирского края осталось всего семь комендатур (Чаинская, Голкинская, Галкинская, Шерстобитовская, Зачулымская, Тегульдетская, Шигарская) и половина спецпереселенцев (42 464 человека, из них 5064 одиночек), они доставляли немало хлопот местным властям. С мая по сентябрь 1930 года из мест ссылки бежало 16115 человек, то есть $27 \%$ спецпереселенцев. Притом большую часть бежавших составляла неженатая одинокая молодежь. Бежавшие семьи чаще всего возвращались к месту прежнего жительства, где пытались восстановиться в правах, беглые же молодые люди рассосались по городам (Бийск, Канск, Минусинск и др.), где многие из них встали на путь политического бандитизма. Только жесткими репрессивными мерами (заключение в концлагерь и внесудебные приговоры) удалось сократить количество побегов [13 Л.28-29.].

Анализируя причины создавшегося положения, начальник Западносибирского краево- 
го административного управления Скрипко на первое место поставил непримиримость кулаков и их активное сопротивление политике выселения, на второе - хозяйственную неустроенность спецпереселенцев. Неспособность комендатур организовать закрепление переселенцев на земле и слабый административный надзор за ними он тоже упомянул, но как второстепенные причины [13 Л.28-29.].

По мнению автора представленной статьи, Скрипко слукавил, преуменьшив проблемы Административного управления в части надзора за ссыльнопоселенцами и «организационного бессилия» по закреплению населения в новых местах. Органы ОГПУ и спецкомендатур оказались неспособны принять и организовать то количество высланных, с которым им пришлось столкнуться: у них не хватило для этого людей и средств. Недаром среди мер по выправлению ситуации Административное управление предложило фактически упразднить в кулацких поселках советскую власть и передать их в прямое управление комендантам Административного управления, утверждаемым Исполнительным комитетом Западносибирского края. Сами же кулацкие поселки предполагалось перевести на полную самоокупаемость [13 Л.30.].

Таким образом, разобранные документы свидетельствуют о том, что коллективизация и раскулачивание в Западной Сибири носили характер системной, всеобъемлющей политики, в осуществлении которой принимал участие весь государственный аппарат, партийный и колхозный актив. Органы ОГПУ осуществляли планирование и координацию операций по выселению. Важную роль играло также «информационное освещение» чекистами происходящих процессов, что позволяло партийно-государственному аппарату корректировать действия местных властей и колхозного актива. В то же время документы иллюстрируют, что органы ОГПУ в Западной Сибири столкнулись с очень серьезными трудностями при размещении раскулаченных: они обязаны были размещать на пустующих землях не только местных кулаков, но и высланных из Европейской части СССР. Для этого не хватало средств и кадров, и ссыльные крестьяне разбегались. Все это создавало дополнительные трудности в работе западносибирских чекистов.

\section{Библиография:}

1. Белковец Л.П. «Большой террор» и судьбы немецкой деревни в Сибири (конец 1920-х-1930-е годы) [Текст] / Л.П. Белковец-М.: ЛА «Варяг», 1995. - 316 с.

2. Бруль В.И. Немцы в Западной Сибири. [Текст] / В.И. Бруль-Топчиха : Топчихинская типография, 1995. - 192 с.

3. Василевский В.П. Деятельность органов ГПУ-ОГПУ в Омском Прииртышье (1922-1934 гг.) [Текст] / В.П. Василевский Диссертация на соискание ученой степени к.и.н. - Омск, 2015. - 291 с.

4. Зима В.Ф. Человек и власть в СССР в 1920-е - 1930-е годы: политика репрессий [Текст] / В.Ф. Зима. - М.: Собрание, 2010. -238 c.

5. Красильников С.А. Серп и Молох. Крестьянская ссылка в Западной Сибири в 1930-е годы [Текст] / С.А. Красильников М.: РОССПЭН, 2003. - 288 с., илл.

6. Красильников С.А., Ушакова С.Н. Крестьянская семья на спецпоселении. Итоги «первой пятилетки» (1931-1935 гг.) [Текст] // Адаптации населения в Сибири: этапы, механизмы, результаты: Сборник научных трудов / Редкол.: Красильников С.А., Попков Ю.В., Шелегина О.Н.; РАН. Сиб. отд-ние. Объединен. ин-т истории, филологии и философии. Ин-т археологии и этнографии.-Новосибирск, 2003. - С.72-86.

7. Лубянка. Сталин и ВЧК-ГПУ-ОГПУ-НКВД. Архив Сталина. Документы высших органов партийной и государственной власти. Январь 1922 - декабрь 1936 [Текст] / Под ред. акад. А.Н. Яковлева; сост.: В.Н. Хаустов, В.П. Наумов, Н.С. Плотникова. - М.: МФД, 2003. - 912 с.

8. Озерова О.А. Роль партийных и советских организаций в раскулачивании и репрессиях тюркских народов Западной Сибири (1928 - 1932 гг.) [Текст] / О.А. Озерова // Омский научный вестник. 2012. Серия Общество. История. Современность. № 4 (111). С. 28-32.

9. Озерова О.А. Применение насильственных методов и репрессий в период сплошной коллективизации в 1930-1932 гг. (на примере тюркских народов Западной Сибири) [Текст] / О.А. Озерова // Омский научный вестник. 2012. Серия Общество. История. Современность. № 5 (112). С. 22-25.

10. Озерова О.А. К вопросу об организации информационной и агентурной работы среди тюркского населения партийными и советскими органами Западной Сибири (конец 1920-х - 1930-е гг.) [Текст] / О.А. Озерова // Омский научный вестник. 2014. Серия Общество. История. Современность. № 1 (125). С. 17-19.

11. Папков С.А. Обыкновенный террор. Политика сталинизма в Сибири [Текст] / С.А. Папков.-М.: РОССПЭН, $2012 .-440$ с.

12. Шангин М.С. Террор против совести: Об уничтожении духовенства и трудового крестьянства в г. Омске и области [Текст]: Сб. документальных материалов / М.С. Шангин-Омск : Омск. кн. изд-во, 1994. - 319 с.

13. Государственный архив Новосибирской области (Далее - ГАНО). Ф. П-3.-Оп 2.-Д.238.

14. ГАНО. Ф. П-З.-Оп 2.-Д.362.

15. ГАНО. Ф. П-3.-ОП.2.-Д.535. 


\section{Исторический журнал: научные исследования № 2 (32) • 2016}

DOI: $10.7256 / 2222-1972.2016 .2 .17518$

\section{References (transliterated):}

1. Belkovets L.P. «Bol'shoi terror» i sud'by nemetskoi derevni v Sibiri (konets 1920-kh-1930-e gody) [Tekst] / L.P. Belkovets-M.: LA «Varyag», 1995. - $316 \mathrm{~s}$.

2. Brul' V.I. Nemtsy v Zapadnoi Sibiri. [Tekst] / V.I. Brul'-Topchikha : Topchikhinskaya tipografiya, 1995. - $192 \mathrm{~s}$.

3. Vasilevskii V.P. Deyatel'nost' organov GPU-OGPU v Omskom Priirtysh'e (1922-1934 gg.) [Tekst] / V.P. Vasilevskii - Dissertatsiya na soiskanie uchenoi stepeni k.i.n. - Omsk, 2015. - $291 \mathrm{c}$.

4. Zima V.F. Chelovek i vlast' v SSSR v 1920-e - 1930-e gody: politika repressii [Tekst] / V.F. Zima. - M.: Sobranie, 2010. - 238 s.

5. Krasil'nikov S.A. Serp i Molokh. Krest'yanskaya ssylka v Zapadnoi Sibiri v 1930-e gody [Tekst] / S.A. Krasil'nikov - M.: ROSSPEN, 2003. - 288 s., ill.

6. Krasil'nikov S.A., Ushakova S.N. Krest'yanskaya sem'ya na spetsposelenii. Itogi «pervoi pyatiletki» (1931-1935 gg.) [Tekst] // Adaptatsii naseleniya v Sibiri: etapy, mekhanizmy, rezul'taty: Sbornik nauchnykh trudov / Redkol.: Krasil'nikov S.A., Popkov Yu.V., Shelegina O.N.; RAN. Sib. otd-nie. Ob"edinen. in-t istorii, filologii i filosofii. In-t arkheologii i etnografii.-Novosibirsk, 2003. - S.72-86.

7. Lubyanka. Stalin i VChK-GPU-OGPU-NKVD. Arkhiv Stalina. Dokumenty vysshikh organov partiinoi i gosudarstvennoi vlasti. Yanvar' 1922 - dekabr' 1936 [Tekst] / Pod red. akad. A.N. Yakovleva; sost.: V.N. Khaustov, V.P. Naumov, N.S. Plotnikova. - M.: MFD, 2003. $-912 \mathrm{~s}$

8. Ozerova O.A. Rol' partiinykh i sovetskikh organizatsii v raskulachivanii i repressiyakh tyurkskikh narodov Zapadnoi Sibiri (1928-1932 gg.) [Tekst] / O.A. Ozerova // Omskii nauchnyi vestnik. 2012. Seriya Obshchestvo. Istoriya. Sovremennost'. № 4 (111). S. 28-32.

9. Ozerova O.A. Primenenie nasil'stvennykh metodov i repressii v period sploshnoi kollektivizatsii v 1930-1932 gg. (na primere tyurkskikh narodov Zapadnoi Sibiri) [Tekst] / O.A. Ozerova // Omskii nauchnyi vestnik. 2012. Seriya Obshchestvo. Istoriya. Sovremennost'. № 5 (112). S. 22-25.

10. Ozerova O.A. K voprosu ob organizatsii informatsionnoi i agenturnoi raboty sredi tyurkskogo naseleniya partiinymi i sovetskimi organami Zapadnoi Sibiri (konets 1920-kh - 1930-e gg.) [Tekst] / O.A. Ozerova // Omskii nauchnyi vestnik. 2014. Seriya Obshchestvo. Istoriya. Sovremennost'. № 1 (125). S. 17-19.

11. Papkov S.A. Obyknovennyi terror. Politika stalinizma v Sibiri [Tekst] / S.A. Papkov.-M.: ROSSPEN, 2012. - 440 s.

12. Shangin M.S. Terror protiv sovesti: Ob unichtozhenii dukhovenstva i trudovogo krest'yanstva v g. Omske i oblasti [Tekst]: Sb. dokumental'nykh materialov / M.S. Shangin-Omsk: Omsk. kn. izd-vo, 1994. - 319 s.

13. Gosudarstvennyi arkhiv Novosibirskoi oblasti (Dalee - GANO). F. P-3.-Op 2.-D.238.

14. GANO. F. P-3.-Op 2.-D.362.

15. GANO. F. P-3.-Op.2.-D.535. 